\title{
NEUROSCIENCE AND MANAGEMENT: CHALLENGES FOR BEHAVIOURAL RESEARCH IN ORGANIZATIONS
}

\author{
David Naranjo-Gil, Laura Gómez-Ruiz, María Jesús \\ Sánchez-Expósito ${ }^{\mathrm{a}}$
}

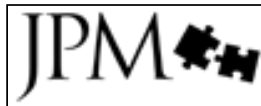

JOURNAL

OF POSITIVE

MANAGEMENT

Vol. 2, No. 1, 2011, pp. 45-58 (C) Copyright by Wydawnictwo Naukowe

Uniwersytetu Mikołaja Kopernika
2083-103X

a Pablo de Olavide University, Business Administration Department,

Sevilla, Spain,

corresponding author: David Naranjo-Gil, e-mail: dnargil@upo.es

\begin{abstract}
The objective of this paper is to explore how the application of neuroscience to management research can facilitate a better understanding of some issues concerning to people behaviour in organizations. In recent years, the ability of researchers to directly observe brain activity has increased tremendously. This paper presented extant neuroscientific findings and showed some examples on how they could be incorporated into management research. We present two studies on honesty and social loafing in teams to inform management researchers when and how neuroscientific methods can complement traditional empirical approaches such as interviews or surveys.
\end{abstract}

Key words: Neuroscience, Behavioural Management, Honesty, Social loafing

Paper type: Conceptual paper

\section{Introduction}

Management research on organizational behaviour has been based widely on rational economic models, where individuals are expected to make decisions considering every piece of available information (Luft and Shields, 2009). However, people often seem to make irrational decisions. Individuals typically invest or buy things moved by their desires or emotions. Over $90 \%$ of the decisions we make are directly or indirectly induced by our subconscious, but people try to justify with economic or logical reasons. In this sense it has been shown that individuals tend to use heuristics to reduce complex problems to simple decisions, and thus they are affected by many biases, such as risk perception or overconfidence (Sharot, Delgado and Phelps, 2004; Luft and Shields, 2009). These biases cannot be ignored because they can have negative consequences for organizations and business, as it was evidenced by the sub-prime mortgage crisis.

The differences between the predictions of traditional economy research and rational behaviour have actually facilitated to develop a strong stream of research, which is called behavioural economy. This stream focuses on analyzing 
NEUROSCIENCE AND MANAGEMENT

David Naranjo-Gil et al. actual behaviours and decision making rather than predict optimal behaviour of individuals (Pennings, García and Hendrix, 2005). It is based on observing the actual behaviour to draw conclusions and develop new models that demonstrate the relationship between the optimal expected outcome the observed anomalous behaviour of economic agents. Unlike the traditional economy and managerial research, which holds that people make decisions in the absence of emotions, behavioural research has shown that many organizational decisions respond to emotional stimuli or unconscious desires (Simon, 1995; Pennings et al., 2005).

Behavioural researchers in management have been extensively based on cognitive psychology and more recently in neuroscience. These three sciences (economics, psychology and neuroscience) explain different aspects of a new field called neuroeconomics (Harrison and Ross, 2010). Technological advances and a better understanding of brain functioning has helped to develop the field of neuroeconomics, which allows us to analyze business problems using techniques of neuroscience, and thus let us to predict the impact of various decisions and policies in the subconscious of individuals (Harrison, 2008). Most organizations use traditional research and business methods, such as surveys or interviews, where the subjective and inaccurate responses are very common. The use of neuroscience techniques can enhance our knowledge about the impact of corporate activities in the conduct and behaviour of individuals (Harrison and Ross, 2010). Among the techniques used we can highlighted the electroencephalogram (EEG), which can measure the bioelectrical activity of the frontal lobe, which is related to the level of attention and emotions. The Functional magnetic resonance imaging (fMRI) is a technique which measures changes in oxygenation of the blood and let researchers to visualize brain activity in real time. These methods provide insights into brain structure and its implications for behaviour and decision making of individuals in organizations (Glimcher and Rustichini, 2004).

This paper tries to explore the potential contribution of neuroscience to management knowledge. In a time in which several research areas in economics and business, recognize the advantages of neuroscientific research methods, this paper review the theoretical, methodological and empirical potential of neuroscientific analyses in management research. Methodical advancements in this field allow researchers to open up what has been considered a 'black box' thus far. While much remains to discover, joint research efforts of economist, cognitive psychologists and neuroscientists have resulted in discovery of brain areas and systems that participate in cognitive processes like conscious decision making, coping with risk and uncertainty, intertemporal choice, and reward and punishment (Kuorikoski and Ylikoski, 2010; Luft and Shields, 2009). These concepts are central to behavioural management research, which typically seeks to understand how humans behave in organizations, make decisions, estimate the future, evaluate the past under a variety of incentives. Since management research 
is increasingly building on fundamental insights from behavioural economics, exploring the potential and feasibility of neuroscientific techniques seems to be the logical next step (Kuorikoski and Ylikoski, 2010).

The objective of this paper is to discuss whether management researchers need to use neuroscience techniques to know better the brain activity and human behaviour in organizations. In this line, this paper contributes to the literature by contemplating the introduction of neuroscience to management research.

The rest of this paper is structured as follow. The Section 2 presents an overview of the brain structure and the different techniques that neuroscientists use for measuring brain activity. Section 3 introduces the case of neuroeconomic and neuromanagement as research fields that analyze the relationship between brain activity and decision making. Section 4 presents several potential applications of neuroscience to extend previous studies in management that used experiment and psychology to measure people behaviour in organizations. Finally, it is shown the discussion and conclusions of the paper.

\section{Neuroscience and Brain Activity Measurement}

The neuroscience analyzes the nervous system, consisting of brain, spinal cord, and nerves, which is crucial for life as it enables people to sense, move, and think (Bear, Connors and Paradiso, 2007). The human brain is a relatively small part in the human body, which folds inside the skull, which acts as physical protection. We can distinguish different parts of the structure of the brain, without claiming to be exhaustive, we find the cerebral cortex, related to the functions of thinking and perception, the limbic system and hypothalamus, associated with emotional behaviour, the hippocampus, and memory-related learning, and the frontal lobe related to attention and emotions (Purve et al., 2004; Bear et al., 2007). Neuroscience literature has identified the prefrontal cortex and the limbic system as major decision-making areas, which are respectively responsible for

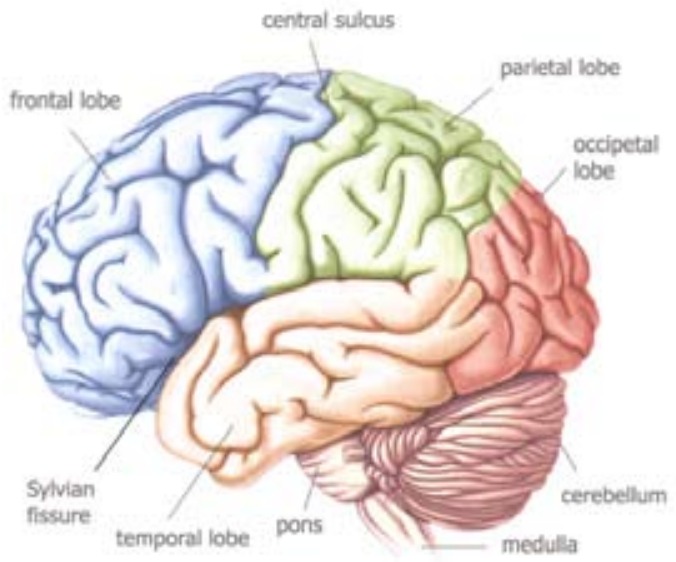

NEUROSCIENCE AND MANAGEMENT

David Naranjo-Gil et al. 
NEUROSCIENCE AND MANAGEMENT

David Naranjo-Gil et al. the cognitive (i.e. thinking and calculation) and emotional (i.e. feeling) aspects of decision-making (Purve et al., 2004, Bear et al., 2010). Figure 1 shows an image of the main areas of human brain.

Human brain can be divided into grey matter (neurons) and white matter (axons and dendrites, the connections between neurons). Grey matter makes up for $40 \%$ of the brain, but consumes $94 \%$ of the brain's oxygen owing to the electrical impulses that allow neurons to communicate with each other (Bear et al., 2007). Purves et al. (2004) showed that most emotional responses are almost automatic. They emanate from the brain's limbic structure, which is grey matter in the medial temporal lobe, and includes the amygdala (linked to emotions), hippocampus (linked to long-term memory) and cingulate cortex (linked to attention).

Knowing how the nervous system works requires understanding of how single neurons interact and behave. However, since the human brain is composed of billions of neurons, it is impossible to explore each and every neurons to figure out how the human brain works (De Martino, Dhashan, Seymour and Dolan, 2006). Thus, critical advances in neuroscience are made by working at different levels of organization. Following Purves et al. (2004) and Bear et al. (2007) we can divide neuroscience research in five types: molecular, cellular, systems, behavioural, and cognitive neuroscience.

Molecular neuroscience studies the brain at its most elementary level. It explores different molecules that play various crucial roles for brain function: Messengers that allow neurons to communicate with one another, series that control what materials can enter or leave neurons, conductors that orchestrate neuron growth, or archivists of past experience (Bear et al., 2007). Cellular neuroscience focuses on how neurons differ in functions, how they influence each other, or how neurons become wired to-gether during fetal development (Purve et al., 2004). System neuroscience analyzes how groups of neurons form complex circuits that perform a common function (breath, speak, view...), this type of neuroscience examines how different neural circuits are related to different forms of perceptions of the external world perceptions or different way of making decisions. Behavioural neuroscience examine the biological bases of behaviour, that is it explores how the different neural systems work together to produce integrated behaviours. Finally, cognitive neuroscience examines how neural substrates produce mental processes (Gazzaniga, Ivry and Margun, 2002). Cognitive neuroscience used advanced brain imaging techniques to document how the activity of different brain regions correlates with specific sensorial and cognitive processes and how the resultant individual activity of different brain regions could be concerted and coordinated through different anatomical pathways to produce a consistent behaviour. 
Since the brain is the centre of the nervous system, it is not surprising that huge efforts have been undertaken to measure activity within this organ. Thanks to technological advances, noninvasive brain imaging has become possible and is currently being applied in a number of fields within the behavioural sciences, many of which are overlapping in their focus of study (McCabe, 2008).

\section{Brain activity measurement}

Neuroscientists use different techniques to analyze the nervous system and brain activity. We now describe briefly the non-invasive methods commonly used to measure brain activity, which have been used in business and managementbased studies, such as Transcranial Magnetic Stimulation (TMS), Functional Magnetic Resonance Imaging (fMRI), Position Emission Tomography (PET) and Magnetoencephalography (MEG).

Transcranial Magnetic Stimulation (TMS) simulate lesions in a specific brain region, whose effects on behavioural performance can be studied. This method is based on the fact that neurons communicate with each other via electric signals. TMS induces electric currents in predetermined brain areas by means of a magnetic pulse through a coil placed on the subject's head,. This technique only allows the perturbation of superficial parts of the cortex (Bear et al., 2007; Purves et al., 2004).

Functional Magnetic Resonance Imaging (fMRI), which capture data as blood oxygen jevel Dependent signals that indirectly measure regional neural and synaptic activity by investigating the amount of oxygenated to deoxygenated blood (Zak, 2004). The change from oxy- to deoxy-hemoglobin happens mainly in brain regions where oxygen is consumed because cells are active, and the scanner is capable of localizing these regions. The main goal of fMRI is to detect local variations of the blood oxygen level signal in the brain and their potential correlation with a given task (Bear et al., 2007; Zak, 2004).

Positron Emission Tomography (PET) is a technique where subjects are injected with a radioactive isotope that emits positrons, which are positively charged electrons (Zak, 2004). When a positron meets an electron they annihilate each other and emit gamma rays. Following Zak (2004) and Bear et al. (2007) when neurons fire they deplete glucose and oxygen and require increased blood flow to resupply these substances. Blood flows to neurons more or less proportionally to their firing rates. PET measures the accumulation of the radioactive tracer in brain regions. Regions metabolizing glucose faster receive more blood flow and emit more gamma rays. A computer algorithm constructs the measurements of regional cerebral blood flow in three dimensions as an indirect measure of neural activity. Since radioisotopes decay quickly, PET experiments are limited in time and have to be conducted within an hour. Furthermore, since radioactive isotopes

NEUROSCIENCE AND MANAGEMENT

David Naranjo-Gil et al. 
NEUROSCIENCE AND MANAGEMENT

David Naranjo-Gil et al. are used subjects are restricted just to a couple of experiments a year (Purves et al., 2004).

Magnetoencephalography (MEG) measures extremely small magnetic fields using small coils called superconducting quantum interference devices, which need to be maintained at low temperature inside a drawer filled with liquid helium. Up to several hundreds of those quantum devices can be placed inside a solid helmet where subjects put their head. MEG measures the contribution of primary post-synaptic currents and only from the cortical regions where the cell columns are arranged tangentially to the skull (Braeutigam, Stins, Rose, Swithenby and Ambler, 2001).

\section{Neuroeconomics and Neuromanagement}

Neuroeconomics converged as a new field from three decision sciences: economics, psychology and neuroscience (Camerer, Loewenstein and Prelec, 2005). While economics tries to describe globally all choice behavior with a single mathematical model, psychology examines the ways in which subjective and objective estimates of value differ and posits psychological modules that can account for these observed behavioural preferences. The neuroscientific explanation of choice behaviour finally, starts with the simplest possible neural circuit that can account for the simplest measurable elements of behaviour (Camerer et al., 2005; Glimcher and Rustichini, 2004). Thus, Neuroeconomics is a multidisciplinary research field incorporating neuroscience, economics, and psychology aimed at developing an understanding of how we make choices. It looks at the brain when we evaluate decisions, categorize risks and rewards, and when we interact with others (Harrison and Ross, 2010; Glimcher and Rustichini, 2004).

By combining techniques from cognitive neuroscience and experimental economics neuroeconomists examine neural activity in real time, observe how this activity depends on the economic environment, and test hypotheses about how the emergent mind makes economic decisions (Harrison, 2008). Neuroeconomics allows us to better understand both the wide range of heterogeneity in human behaviour, and the role of institutions as ordered extensions of our minds. In the field of neuroeconomics, we can find two extremes when scholars address the question whether neuroscience is the new road to take within the study of behaviour in general and in economics in particular, or if it is, in fact, just a fashion trend inspired by what is technologically possible within that field. In one extreme we can find authors who would like to see standard economics completely isolated from other disciplines. These authors asserted that brain mechanisms by themselves cannot offer evidence against transitivity of preferences or any other choice-theoretic assumption (Harrison and Ross, 2010; Harrison, 2008). On the other extreme, several authors argued that neuroscience could have the potential 
to provide the grand theory that eventually unifies all behavioural sciences (e.g. economics, sociology, psychology...) around a common brain-based model of how people take decisions (Gintis, 2007; Camerer et al., 2005). With today's technologies, neuroscience has an increasing ability to see inside people's brains and it is possible to show, how brain activity produces economic decisions (Harrison and Ross, 2010).

Through the use of the results obtained from brain studies in combination with the according choice made by the decision maker, neuroeconomists can facilitate our understanding of the deliberation process and that results can eventually be used to improve economic models (Harrison and Ross, 2010; Camerer et al., 2005). The insights gained by measuring brain activity during choice, neuroeconomic studies will lead to improved behavioural models which will get closer to using appropriate presumptions regarding human nature during choice, making economic models empirically driven. By putting human beings back into economics, they argue, predictions are sharpened and controversies can be resolved (Harrison, 2008)). In this vein, McCabe (2008) asserted that by moving the study of decision making to the brain, neuroeconomics will put more structure on preferences, encoding of information, and cognition, and thus will make economic theory more predictive and consequently more useful.

Several authors, such as Aydinonat (2010) or Harrison and Ross (2010) see various ways how neuroeconomics could contribute to economics. Firstly, the neural mechanisms of measurement could appear to implement rational-choice theories. That is, some kinds of choices could turn out to be mechanistically implemented in ways that match familiar math and observed behaviour. Aydinonat (2010) suggests that by asking different questions to economic phenomena, neuroeconomics expands the set of questions that we are able to answer concerning economic real world. Furthermore, an application of neuroeconomics to business and organization problem is the origin of the Neuromanagement as a research field in management.

Researcher in neuromanagement analyze the application of neuroscience to business management, which required neuroscience specialists think about the business world and at the same time, managers think about neuroscience. Research on management has been relying on psychology and cognitive theories and research methods for many years (Birnberg, Luft and Shields, 2007; Aydinonat, 2010). The application of neuroscience to manage will help us to understand better questions such as how can we make decisions efficiently? How to manage people to implement changes in organizations? How to create a team-based structure to enhance organizational performance? We can say that under the term neuromanagement, research on organizational behaviour is combined with neuroscience and the states and processes within the organism of employees and managers are made measurable. Constructs such as attitude, emotions, honesty

NEUROSCIENCE AND MANAGEMENT

David Naranjo-Gil et al. 
NEUROSCIENCE AND MANAGEMENT

David Naranjo-Gil et al. and risk-aversion are analyzed (Harrison and Ross, 2010). In the following section we explore the application of a neuroscience approach to behavioural issues in management, such as honesty and social identity in teams.

\section{Neuroscience and Behavioural issues in Management: The case of Honesty and Social loafing in teams}

\section{Honesty Management and Neuroscience}

Due to the existence of several business scandals, the reporting behaviour has captured the attention of the general public. Individuals have private information they can use to their self-interest, even if it harms the organization. In many organizations, managers have some discretion in reporting the results of their unit. The managers can, for example, select deprecation methods or make provisions and reservations in anticipation of future expenses (Bowen, Rajgopal and Venkatathalam 2008). The individuals can use these possibilities in order to provide a positive impression of the results. It is therefore important to analyze in this environment how you can modify the behaviour of individuals so that they report their results in an honest manner (Rankin, Schwartz and Young, 2008). Honesty could be defined as the tendency of individuals to avoid making untrue factual assertions, despite explicit or implicit incentives to the contrary (Rankin et al., 2008).

Recently, studies have begun to suggest that incentives and control systems that are designed based on the assumption that managers only value their own gain and that they act opportunistically to maximize their profits are not always optimal (Rigdon, 2009). Individuals balance the financial benefits of lying with the psychic benefits of honesty, for which they will not be completely honest, but will not be as dishonest as predicted by pure selfishness, as has been demonstrated by Hannan, Rankin and Towry (2006) and Rankin et al. (2008). Social neuroeconomics tries to understand the brain processes that govern these regular deviations from purely self-interested behaviour (Fehr and Camerer, 2007). Individuals are faced with a conflict of priorities or dilemma, on one hand they prefer to be honest in order to meet their internal value systems and on the other hand, are tempted by the economic benefits of behaving dishonestly (Mazar, Amir and Ariely, 2008). The brain must compare social motives and economic self-interest and resolve the conflict between them (Fehr and Camerer, 2007).

Therefore, the neuroscience approach can help us better understand how and why individuals take into account other aspects that can influence in the behaviour of individuals other than the maximization of economic gains. Given the neuroscientists' knowledge of the function of the brain centres, conclusions can be drawn about what underlies the observed behaviour. Linking neuroscience to management could help us to know why individual are not as completely dishonest as is predicted by traditional economic theory. 
A possible explanation of this happens could be given due to the fact that the individuals are not motivated only for monetary incentives as is demonstrated in several studies, but they have social preferences that influences their behaviour (Fehr and Camerer, 2007). In neuroeconomic literature we can find studies in which they find that there is substantial overlap between areas activated by social reward and activation observed in studies of reinforcement learning or anticipated money reward (Fehr and Camerer, 2007). For this, due to the fact that honest reporting induced by monetary incentives can be costly (Luft and Shields, 2009), an alternative could be to use non-monetary incentives which reinforce the social preferences of people to be honest. A way to achieve this is through the design of management control system, such as beliefs system and boundary systems defined by Simons (1995). We can test this with a behavioural experiment, but we can enhanced our results using functional magnetic resonance imaging (fMRI) because we can obtain a objective measure about if the beliefs system and the boundary system motivate to people to be more honest.

The application neuroscience approach has several advantages. It rejects the premise of unobservability from economic theory, and seeks a microfoundation of social and economic neural circuitry (Fehr and Camerer, 2007). Combining the methods of neuroscience and economics generates powerful tools for studying the brain processes behind human social interaction (Fehr and Camerer, 2007). Economics and others social sciences might benefit from social neuroeconomics because of the potentially unifying force of neural data for choice-based approaches (Luft and Shields, 2009).

\section{Managing Social loafing in teams: A neuroscience approach}

The propensity of an individual to withhold effort has been defined as the likelihood that an individual will give less than full effort on a job related task (Kidwell and Valentine, 2009). Variants of this phenomenon include free rider and social loafing. The difference among the concepts is the reason for, or context in which, a lack of participation or a drop in effort occurs. In the social loafing process a person withholds effort as he or she moves from an individual performing alone to individuals performing in groups (Williams and Karau, 1991). Social Impact Theory provides a theoretical explanation of the social loafing process. This theory proposes that changes in behaviour or opinion (the social impact) of group members are a function of the strength (number and power) and distance (physical or psychological) of group members. Related to distance, when distance increases between team members, the ability of members to engage in social comparison is reduced (e.g. an individual evaluate themselves against similar others). There are affective and behavioural reactions to the comparison process. If the distance is reduced between team members, social comparison is enhanced and acts as an affective bonding influencing individual behaviour (Chidambaram and Tung, 2005).
NEUROSCIENCE AND MANAGEMENT

David Naranjo-Gil et al. 
NEUROSCIENCE AND MANAGEMENT

David Naranjo-Gil et al.
In this section we provided evidence of two processes related to the social loafing effect in teams, social identity and the use of management control system, related to psychology the former and to accounting the latter. On one hand, social identification is an important part of one's self-concept and is derived out of group memberships (Van Dick, Tissington and Hertel, 2009). If team members feel the team as a whole, individuals feel near. In this sense, social identification turns the group, psychologically, into a part of the self and reduces the psychological distance between team members (Van Dick et al, 2009). On the other hand, following Simons' framework (1995) several researchers described the interactive use of management control systems as an integrative liaison device that breaks down the functional and hierarchical barriers between individuals. The dialogue and communication which characterized an interactive use of management control systems is consistent with the operation of group contexts (Simons, 1995). We can expect social identity and the interactive use of management control systems reduce distance between team members, creating a cooperative context versus a competitive context, and influencing individuals' effort. Further, several researchers have stressed that the influence of organizational and psychological variables through teams outcomes are not directed, but mediated through other processes conceived of as motivational and affective states (Meyer, Becker and Vandenberghe, 2004). Commitment is a motivational and affective state which in turn influences job performance (Meyer et al., 2004). Thus, we propose that the effects of social identity and the interactive use of management control system on the social loafing process are mediated by the team affective commitment.

In Neuromanagement the decision of the individual is the stimulus and the brain centre activation is the response. Moreover, while the respondent in brain imaging studies is always the individual, brain imaging tools are not constrained by the individual level, but they may extend to other levels of analysis by relying on hyper-scanning to simultaneously scan several individuals that are part of a certain group. Neuroscience literature focuses on the localization and functionality of the brain areas that underlie decision-making, cognitive, emotional, and social processes. Thus, applying neuroscience to management research we have an opportunity of linking a mental process into one or more brain areas (Dimoka, Pavlou and Davis, 2010). In the case of social loafing and management control system, we expect the manipulation of our different conditions creates different contexts, a cooperative context (high salience of social identity, high interactive use or both) and a competitive context (low salience of social identity and low interactive use). Decety, Jackson, Sommerville, Chaminade and Meltzoff (2004) using a fMRI (functional Magnetic Resonance Imaging) demonstrate that the mental framework implicated in cooperation is associated with specific left medial orbitofrontal cortex involvement. Contrary, the mental framework of competition revealed activation in the right inferior parietal cortex. Moreover, this region is 
activated when individuals observe confusion between one's own action and its visual consequences. And this is one of the features of the social loafing process (individuals may have felt lost in the group and unable to observe their fair share of the positive consequences to working hard). Following Decety et al. (2004), through the use of fMRI we can control which brain area is activated related to cooperation or competition. That is, we can expect individuals, who feel in a competitive context, are those who develop high levels of shirking behaviour. Moreover, we can contrast the manipulation of our conditions. We can manipulate conditions to create different levels of cooperative and competitive context. We can expect to find more shirking behaviours in the low interactive use condition and in the low salience of social identity condition. Thus, we can test if the right inferior parietal cortex is activated in individuals of these conditions. We know that researchers used self-reported questionnaires to check the manipulation of conditions of the experiment. And self-reported data suffer from subjectivity bias, social desirability bias, common method bias, and demand effects. Thus, researchers should seek convergent validity by linking fMRI data to other behavioural measures (Dimoka et al., 2010).

Finally, Sharot et al. (2004) demonstrated that the brain area named limbic system has generally been linked to emotional and social processes, whereas the prefrontal cortex has been associated with cognitive process. In the case of social loafing, team members develop a cognitive task, thus it seems reasonable to think that prefrontal cortex should be activated. Further, if we use fMRI we could also check if limbic system is activated. If this occur, we can suggest as explanation that the manipulated conditions, that is social identity or/and the interactive use of management control system influence the activation of this brain area, suggesting that the construct of affective commitment is also present (Dimoka et al., 2010).

\section{Discussion and Conclusions}

The objective of this paper was explore how the application of neuroscience to management research can facilitate a better understand of some issues concerning to people behaviour in organizations. In recent years, the ability of researchers to directly observe brain activity has increased tremendously. There are various techniques to measure brain activity, which differ in cost, accuracy, impact on study subjects, complexity, and time. The current state of neuroscience and organizational behaviour is at the beginning, although the number of studies published has been increasing in recent years, there is only limited evidence available on selected topics on management research.

A very important field in neuroscience draws on visualization techniques of brain activity during human task execution to explain the role that neural subsystems and circuits play in human judgment and organizational behaviour. Measuring brain activity in management experiments is thus technically possible

NEUROSCIENCE AND MANAGEMENT

David Naranjo-Gil et al. 
NEUROSCIENCE AND MANAGEMENT

David Naranjo-Gil et al. and redundancy can be ruled out. The application of neuroscience techniques to management research has shown that there are many critical voices still questioning the approach of adding neuroscience to behavioural research in organizations. It is still not clear, how knowing which part of the brain is more active in certain circumstances could advance management research. Many experimental studies in management research build their hypotheses on theories from behavioural economics and psychology. The impact of emotion and cognition are thereby mostly taken for granted. With the possibilities neuroscience offers, behavioural results that have so far been taken as a given could be explained on the basis of the underlying brain patterns.

This paper presented extant neuroscientific findings and showed some examples on how they could be incorporated into management research. Thus, we try to introduce the management researchers into a field that may otherwise be judged as inaccessible. Neuroscientific analysis is clearly a blind spot in contemporary management research, we believe that understanding the interplay between brain and nervous system allows us with a more fundamental understanding of the origins of decision making and behavior in organizations (Harrison and Ross, 2010).

The case on honesty and social loafing we presented in this paper can inform management researchers when and how neuroscientific methods can complement traditional empirical approaches such as experiments or surveys. Thus we can contribute to enhance validity of established construct in management research by confirming their mode of functioning, but also to uncover potential differences between existing management constructs and brain mechanisms (Dimoka et al., 2010).

This paper has provided a general explanation to management research what neuroscience is, how neuroscience views the brain as the seat of human affective and cognitive processes, what observation techniques exist within neuroscience, and how variables and processes observed in neuroscience relate to variables and concepts in extant management research. We have discussed the caveats of applying neuroscience to management research. Overall, this paper may serve as a general research agenda to aid management researchers who are interested in conducting neuroscientific research to evaluate its prospects.

\section{References}

Aydinonat, N. E. (2010), "Neuroeconomics: more than inspiration, less than revolution", Journal of Economic Methodology, Vol. 17 No. 2, pp.159-169.

Bear, M., Connors, B. \& Paradiso, M. (2007), Neuroscience: Exploring the Brain, $3^{\text {rd }}$ ed. Lippinccot Williams and Wilkins, PA, Philadelphia.

Birnberg, J. G., Luft, J. and Shields, M. D. (2007), "Psychology Theory in Management Accounting Research", in: Chapman, C. S., Hopwood, A. G. and Shield, M. D. (Eds.), Handbook of Management Accounting Research, Elsevier, Oxford, pp. 113-136. 
Bowen, R., Rajgopal, S. \& Venkatathalam, M. (2008), “Accounting Discretion, Corporate Governance, and Firm Performance", Contemporary Accounting Research, Vol. 25 No. 2, pp. 351-405.

Braeutigam, S., Stins, J., Rose, S. P. R., Swithenby, S. J., \& Ambler, T. (2001), "Magnetoencephalographic Signals Identify Stages in Real-Life Decision Processes", Neural Plasticity, Vol. 8 No. 4, pp. 241-254.

Camerer, C. F., Loewenstein, G. \& Prelec, D. (2005), "Neuroeconomics: How Neuroscience Can Inform Economics", Journal of Economic Literature, Vol. 43 No. 1, pp. 9-64.

Chidambaram, L. \& Tung, L.L. (2005), "Is out of sight, out of mind? An empirical study of social loafing in Technology-supported groups", Information System Research, Vol. 16 No. 2, pp. 149-168.

Decety, J., Jackson, P.L., Sommerville, J.A., Chaminade, T. \& Meltzoff, A.N. (2004), "The neural bases of cooperation and competition: an Fmri investigation", NeuroImage, Vol. 23 No. 2, pp. 744-751.

De Martino, B., Dhashan, K., Seymour, B. \& Dolan, J. (2006), "Frames, Biases, and Rational Decision-Making in the Human Brain”, Science, Vol. 313 No. 5787, pp. 684-687.

Dimoka, A., Pavlou, P.A. and Davis, F. (2010), "NeuroIS: The potential of Cognitive Neuroscience for Information Research System", Information System Research (Articles in Advances), pp. 1-18.

Fehr, E. \& Camerer, C. (2007), "Social neuroeconomics: the neural circuitry of social preferences", Trends in Cognitive Sciences, Vol. 11, No. 10, pp. 419-427.

Gazzaniga, M. S., Ivry, R. B. \& Mangun, G. R. (2002), Cognitive Neuroscience - The Biology of the Mind (2nd ed.), W. W. Norton \& Company, New York.

Gintis, H. (2007), "A framework for the unification of the behavioral sciences", Behavioral and Brain Sciences, Vol. 30 No. 1, pp. 1-61.

Glimcher, P. W. \& Rustichini, A. (2004), "Neuroeconomics: The Consilience of Brain and Decision”, Science, Vol. 306 No. 5695, pp. 447-452.

Hannan, R.L., Rankin, F.W. \& Towry, K.L. (2006), "The Effect of Information Systems on Honesty in Managerial Reporting: A Behavioral Perspective", Contemporary Accounting Research, Vol. 23 No. 4, pp. 885-918

Harrison, G. W. \& Ross, D. (2010), “The methodologies of neuroeconomics", Journal of Economic Methodology, Vol. 17 No. 2, pp. 185-196.

Harrison, G. W. (2008), "Neuroeconomics: A Critical Reconsideration”, Economics and Philosophy, Vol. 24 No. 3, pp. 303-344.

Kidwell, R.E \& Valentine, S.R. (2009), "Positive group context, work attitudes, and organizational misbehaviour: The case of withholding job effort", Journal of Business Ethics, Vol. 86 No. 1, pp. 15-28.

Kuorikoski, J. \& Ylikoski, P. (2010), "Explanatory relevance across disciplinary boundaries: the case of neuroeconomics", Journal of Economic Methodology, Vol. 17 No. 2, pp. 219-228.

Luft, J. \& Shields, M.D. (2009), "Psychology Models of Management Accounting", Foundations and Trends in accounting, Vol. 4 No. 3-4, pp. 199.

McCabe, K. A. (2008), "Neuroeconomics and the Economic Sciences", Economics and Philosophy, Vol. 24 No. 3, pp. 345-368. 
NEUROSCIENCE AND MANAGEMENT

David Naranjo-Gil et al.
Mazar, N., Amir, O. \& Ariely, D. (2008), "The Dishonesty of Honest People: A Theory of Self-Concept Maintenance", JMR, Journal of Marketing Research, Vol. 45 No. 6, pp. 633.

Meyer, J.P., Becker, T.E. \& Vandenberghe, C. (2004), "Employee commitment and motivation: A conceptual analysis and integrative model", Journal of Applied Psychology, Vol. 89 No. 6, pp. 991-1007.

Pennings, J.M.E., García A. P., Hendrix, E. (2005), "Towards a theory of revealed economic behavior: the economic-neuroscience interface", Journal of Bioeconomics, Vol. 7 No. 2, pp. 113-137.

Purves, D. et al. (2004), Neuroscience, $3^{\text {rd }}$ ed. Sinauer Associates, MA, Sunderlands.

Rankin, F., Schwartz, S. \& Young, R. (2008), "The Effect of Honesty and Superior Authority on Budget Proposals", The Accounting Review, Vol. 83, No. 4, pp. 1083$-1099$.

Rigdon, M. (2009), “Trust and reciprocity in incentive contracting”, Journal of Economic Behavior \& Organization, Vol. 70, No. 1-2, pp. 93-105.

Sharot, T., Delgado, M.R. and Phelps, E.A. (2004). How Emotion Enhances the Feeling of Remembering. Nature Neuroscience, 7, 12, 1376-1380.

Simon, H. A. (1995), "A behavioral model of rational choice", The Quarterly Journal of Economics, Vol. 69, No. 1, p 99-118.

Simons, R. A. (1995), Levers of control: How managers use innovative control systems to drive strategic renewal, MA, Harvard Business School Press, Boston.

Van Dick, R.; Tissington, P.A. \& Hertel, G. (2009), "Do many hands make light work? How the overcome social loafing and gain motivation in work teams", European Business Review, Vol. 21 No. 3, pp. 233-245.

Williams, K.D. \& Karau, S.J. (1991), "Social loafing and social compensation: The effects of expectations of Co-Worker performance", Journal of Personality and Social Psychology, Vol. 61 No. 4, pp. 570-581.

Zak, P. J. (2004), "Neuroeconomics", Philosophical Transactions of the Royal Society of Lon-don Series B: Biological Sciences, Vol. 359 No. 1451, 1737-1748. 